\title{
Passado e presente nas relações Colômbia-Estados Unidos: a estratégia de internacionalização do conflito armado colombiano e as diretrizes da política externa norte-americana
}

Past and present in the Colombia-United States relations:
the strategy of internationalization of the Colombian armed
conflict and the guidelines of North American foreign policy

MARCELO SANTOS*

Rev. Bras. Polít. Int. 53 (1): 67-88 [2010]

\section{Introdução}

O texto a seguir envolve uma tentativa de resgate dos principais temas e fundamentos das relações Colômbia-EUA, com ênfase analítica no período de governo de Álvaro Uribe na Colômbia (2002-...). Aqui, a pretensão não é exatamente uma análise da política externa norte-americana, mas uma reflexão de como um país periférico, como a Colômbia, tem lidado com essa política. Há uma hipótese subjacente nessa análise que aponta para uma interdependência entre os assuntos internos e externos na realidade colombiana, sendo que a forma como se desenvolve essa interconexão tem passado pelo tipo de relação que esse país estabelece com os EUA.

Marcada por divisões geográficas, regionais, culturais, sociais, políticas e econômicas que, na maior parte do tempo, foram equacionadas pela violência, a Colômbia teve ao longo de sua história uma tremenda dificuldade para consolidar sua unidade nacional e para garantir o funcionamento efetivo do seu Estado. Dito de outra forma, o país tem convivido com um duradouro quadro de incapacidade estatal para garantir soberania, mediar conflitos sociais e fazer valer o Estado de Direito em várias partes do seu território, num ambiente de cultura política de violência, de limites de participação política e de acesso desigual aos recursos naturais. Nesse contexto, não é por acaso que a história do país também tem

\footnotetext{
* Professor de Ciência Política da Universidade Estadual Paulista - UNESP (Campus Araraquara) e pesquisador do Instituto Nacional de Ciência e Tecnologia para Estudos sobre os Estados Unidos - INEU (marsant28@yahoo.com.br).
} 
sido marcada pelo surgimento de conflitos armados e pelo desenvolvimento de economias ilegais. Na segunda metade do século XX, depois de ter passado pelos conflitos da Guerra dos Mil Dias (1899-1902) e da Violência Famosa (1948-1965), a Colômbia passou a vivenciar outro conflito interno armado. A partir dos anos 1960, no auge da Guerra Fria e da Doutrina de Segurança Nacional dos EUA, o país viu surgir grupos guerrilheiros de esquerda, seguidos do aparecimento de organizações paramilitares de direita, que passaram a estabelecer combates entre si e com o Estado. Desde então, o conflito armado colombiano tem percorrido várias fases, e sido potencializado pela persistência do quadro descrito acima e pelo desenvolvimento de outros fenômenos, tais como as economias ilícitas do narcotráfico, do tráfico de armas e do contrabando. Pode-se dizer que esse quadro e seus desdobramentos têm como consequência fundamental o aumento da interdependência entre os planos interno e externo da realidade colombiana. Nesse sentido, como esse texto pretende demonstrar, a maneira como se equaciona essa interdependência tem envolvido percepções, estratégias e abordagens políticas que se referem, entre outras coisas, às relaçôes entre a Colômbia e os EUA.

\section{As relações Colômbia-EUA em perspectiva histórica: temáticas e fundamentos}

Quando se analisa a história da política exterior colombiana, logo fica evidente que, em grande parte do tempo, ela esteve permeada por uma forte influência dos EUA. Seja por pragmatismo, convicção ou conveniência das elites políticas e econômicas do país, ou por sugestôes, intervenções ou imposições dos EUA, o fato é que, desde a perda do Panamá, no início do século XX, a Colômbia tem uma relação muito próxima aos norte-americanos. Um capítulo fundamental dessa história está sintetizado na formulação da doutrina Respice Polum, que teve início no governo de Marco Fidel Suarez (1918-1922) e predominou na diplomacia colombiana ao longo do século XX. Segundo essa doutrina, o país deveria adotar um alinhamento incondicional às diretrizes dos EUA em matéria de política externa, sob a convicção de que, além de pertencer à esfera de influência da "estrela polar do norte", a Colômbia poderia tirar grande proveito dessa associação. Os pactos secretos com os EUA durante a Segunda Guerra Mundial, o solitário envio de tropas para a Guerra da Coréia (1951) e a participação ativa na expulsão de Cuba da OEA (1962) constituem alguns bons exemplos de posiçōes colombianas na política internacional afinadas com as diretrizes da potência do norte. Não por acaso, no pós-Segunda Guerra, a Colômbia foi grande receptora de recursos econômicos dos EUA, ficando atrás apenas do Brasil nesse quesito, durante o período 1949-1974 (Pardo y Tokatlian, 1988; Tickner, 2000). Ao longo das décadas de 1970, 1980 e 1990, o espírito da Respice Polum continuou orientando várias gestóes, como a de Turbay Ayala (1978-1982), que tomou medidas como: a assinatura de tratado de extradição com os EUA; o rechaço à declaração 
franco-mexicana, que recomendava uma negociação entre guerrilha e o governo de El Salvador; a participação do país na qualidade de observador nas eleições salvadorenhas de 1982 (com o qual se dava legitimação ao regime ditatorial); o envio de tropas colombianas para a Península do Sinai para ajudar na garantia do cumprimento dos acordos de Camp David sobre a paz no Oriente Médio; a permissão para a instalação de radares norte-americanos em San Andrés, com o objetivo de monitorar o governo sandinista na Nicarágua; e a decisão solitária na América Latina (somente acompanhada pela ditadura Pinochet) de não apoiar a causa Argentina na Guerra das Malvinas (Arana, 2004; Carvajal, 2005/2006).

Distanciando-se de uma visão estática das relaçōes internacionais, é fundamental reconhecer que o predomínio da doutrina Respice Polum não significou que tudo nas relações externas colombianas tenha sido apenas associação aos EUA. Pode-se dizer que, dependendo das condições, conjunturas, objetivos e orientações, alguns governos colombianos estabeleceram diretrizes de política externa de distanciamento e de relativa autonomia em relação aos EUA. Uma diretriz emblemática dessa reorientação foi inaugurada pelo então ministro das relaçóes exteriores do governo de Carlos Lleras (1966-1970) e depois presidente do país, Alfonso López Michelsen (1974-1978). Numa perspectiva de diversificar as relaçõos externas e alcançar uma maior esfera de atuação no sistema internacional, foi elaborada a doutrina Respice Simila, ou seja, mirar as nações semelhantes em grau de desenvolvimento, como a América latina, por exemplo. (Tickner, 2000; Arana, 2004; Ramírez, 2004). Esse é o horizonte em que podem ser entendidas algumas posturas de política externa da gestão Alfonso López, tais como: o apoio sistemático ao Panamá na assinatura do tratado de Carter-Torrijos, no sentido de que esse país assumisse o controle do canal interoceânico; o reatamento das relaçôes diplomáticas com Cuba em 1975; o empenho para avançar nas negociações do Pacto Andino; etc. Também é o clima em que se desenvolveu a política externa de três outros governos colombianos, a saber: o de Belisario Betancur (1982-1986), marcado pela presença ativa da diplomacia colombiana no Grupo de Contadora (1983) e no Consenso de Cartagena (1984), buscando saídas multilaterais para problemas latino-americanos, e também pela formalização da entrada da Colômbia no Movimento dos Países Não-Alinhados; o de Virgilio Barco Vargas (1986-1990), caracterizado por um empenho sistemático e programático de expansão das relações externas do país, sem consideraçōes ideológicas; e o de César Gaviria Trujillo (19901994), que incluiu o país na Associação de Estados do Caribe (AEC) e assumiu a presidência do Movimento dos Países Não-Alinhados. Note-se, no entanto, que essas posições autonomistas no manejo das relações externas esbarraram, muitas vezes, nos limites e nas dificuldades peculiares à diplomacia de países frágeis como a Colômbia, tendo que retroceder posiçôes em temas econômicos, por exemplo, nos quais o poder dos EUA e dos organismos financeiros internacionais impôs duros constrangimentos. Além disso, a ampla relação entre os assuntos internos e a conjuntura internacional - principalmente no que diz respeito ao tema do 
combate às drogas, a partir da década de 1980 - contribuiu decisivamente para a "internacionalização" das questôes internas, condicionando as possibilidades e estabelecendo limites a uma política externa de caráter mais autonomista.

Do lado dos EUA, historicamente, sua política externa na América Latina foi movida por preocupações relacionadas à sua segurança nacional, às suas políticas domésticas e aos interesses de suas grandes empresas, configurando uma história de mudanças periódicas cíclicas, com continuidades e modificações, dependendo de variáveis como o volume de negócios, o grau de adesão das elites latino-americanas, a resistência de vários segmentos sociais latino-americanos, a importância de um determinado país no sistema de segurança hemisférica, etc. Por essas razões que a diplomacia norte-americana nem sempre tratou as distintas regiōes da América Latina de forma homogênea. Em relação à Colômbia - depois de patrocinar a fragmentação do seu território no episódio do canal do Panamá, nos marcos do Big Stick, e, na década de 1930, no horizonte da Política de Boa Vizinhança, de Franklin D. Roosevelt (1933-1945), utilizar o país como um dos grandes fornecedores de matérias-primas (platina e petróleo) fundamentais à sua corrida armamentista - a atenção dos EUA para esse país foi retomada no contexto da Guerra Fria, assumindo a Colômbia como "nação amiga" na sua luta contra as influências de origem soviética no hemisfério. Nessa perspectiva, as Forças Armadas colombianas foram enquadradas na Doutrina de Segurança Nacional norte-americana, com os EUA fornecendo apoio financeiro, militar, técnico e logístico aos militares colombianos para a luta contra grupos sociais e movimentos guerrilheiros de esquerda. Além disso, o país foi palco de programas de cooperação econômica e social, nos marcos da Aliança Para o Progresso, de John F. Kennedy (1961-1963), e de expansões das corporações norte-americanas.

A partir da década de 1970, com o presidente Nixon, os EUA incluíram na sua Doutrina de Segurança Nacional a luta contra a produção e comercialização de drogas ilícitas, fato que teria, nas décadas seguintes, profundas implicações nas suas relações com a América Latina, especialmente com a Colômbia. Com Ronald Reagan (1981-1989), a política de combate às drogas esteve completamente subordinada às diretrizes da política exterior dos EUA. Nesse sentido, o tema das drogas, longe de ser tratado como um problema de saúde pública, de desajuste social ou da própria política proibitiva interna dos EUA, transformou-se numa questão de segurança nacional, pois os estrategistas conservadores logo trataram de relacionar o problema com agentes externos, tais como uma "conspiração de latinos" (Tena, 2000; Rodrigues, 2004).

Em 1982, foi aprovada a Defense Autorization Act, que permitiu ao exército norte-americano participar da luta contra as drogas. Em abril de 1986, o governo Reagan incorporou à doutrina de segurança nacional a National Security Decision Directive (NSDD), que estabelecia a aliança entre terrorismo de esquerda e narcotráfico como uma ameaça letal para a segurança nacional dos EUA. Com a reformulação da doutrina de segurança nacional, a administração Reagan 
aumentou a pressão sobre determinados governos latino-americanos no sentido de erradicar os plantios e reprimir o tráfico de drogas. Além de ameaças do uso da força, pressóes políticas, econômicas e diplomáticas e o treinamento e apoio logístico de forças policiais e militares latino-americanas antidrogas, o governo dos EUA estabeleceu a Certificação. Por meio desse mecanismo, o Congresso norteamericano passou a monitorar e avaliar os esforços antinarcóticos de cada um dos países latino-americanos, suspendendo a assistência econômica, impondo sanções comerciais e vetando empréstimos de organismos internacionais de crédito aos países que não estivessem de acordo com as suas diretrizes. A vitória na Guerra Fria no final da década de 80, selada mais tarde com a queda do muro de Berlin (1989) e a desintegração da URSS (1991), levou, imediatamente, a política externa norte-americana a substituir o comunismo pelo narcotráfico como a grande ameaça proveniente da América Latina à segurança nacional dos EUA. A administração George Bush (1989-1992) retomou a expressão "guerra às drogas" para lançar a National Defense Authorization Act (1989), que mobilizou o Departamento de Defesa na luta contra o narcotráfico. Assim, o mundo pós-guerra fria nascia para a América Latina sob a ingerência da política norte-americana de combate ao narcotráfico. A estratégia militarista repressora de combate à oferta de drogas seria uma poderosa justificativa para a crescente militarização da política de segurança norte-americana na regiāo, tendo a Colômbia como um dos palcos centrais dessa política. O país - com longa tradição contrabandista, localização geográfica com acesso as duas costas dos EUA, terras férteis, clima adequado, mão-de-obra abundante e Estado debilitado - estava se convertendo em um dos maiores centros de produção e tráfico de drogas ilícitas do mundo.

Em decorrência desse cenário, não é difícil perceber que, a partir da década de 1980, a política de segurança dos EUA em relação ao combate às drogas ilícitas iria determinar a agenda desse país para a Colômbia, sobrepondo e influenciando outras temáticas, como democracia, livre comércio e dívida externa. Definitivamente, a crescente participação da Colômbia na produção e no tráfico de maconha, cocaína e heroína e o recrudescimento do seu conflito armado converteram oficialmente o país, aos olhos dos EUA, numa ameaça à estabilidade regional e à segurança nacional norte-americana (Pardo, 1997; Rivillas, 2002; Riaza, 2004).

Apesar de algumas ressalvas iniciais das administrações colombianas de Betancur, Barco e Gaviria em assumir integralmente as definições, diagnósticos e as estratégias norte-americanas acerca do tema do combate às drogas, aos poucos, os governos colombianos foram sucumbindo à visão dos EUA. Isso ocorreu devido à conjunção dos seguintes fatores que se seguem: primeiro, as imensas dificuldades do debilitado Estado colombiano para deter o crescente poder do narcotráfico no país, inicialmente o dos cartéis de Cali e Medellín, e depois o dos inúmeros "micro-cartéis" regionais; segundo, os tremendos recursos econômicos gerados pelo narcotráfico, que, além de contribuírem para exacerbar os históricos índices de violência e de corrupção, também incrementaram o poderio 
dos paramilitares de direita e das guerrilhas de esquerda, fazendo que o conflito interno armado assumisse dimensōes trágicas e gigantescas em números de mortos, feridos, desaparecidos, sequestros, massacres e refugiados; terceiro, as intensas pressões, ameaças e sanções dos EUA, que atingiram o ponto máximo no governo colombiano de Ernesto Samper (1994-1998), no qual os norte-americanos tiraram a Certificação e qualificaram o país como uma "narcodemocracia", o que contribuiu para, entre outras consequências, debilitar ainda mais o Estado colombiano, a perda de credibilidade do país no exterior e a deterioração da situação econômica; quarto, a percepção de determinados grupos sociais, econômicos e políticos colombianos de que a internacionalização da política antidrogas, nos marcos dos EUA, poderia ser vantajosa para a realização dos seus objetivos internos; quinto, a percepção de vários setores da sociedade de que o debilitado Estado colombiano não possuía capacidade para derrotar os grupos armados ilegais, necessitando de ajuda externa para enfrentar o conflito armado interno.

E foi durante os governos de Bill Clinton (1993-2001) e de Andrés Pastrana (1998-2002) que a confluência desses fatores desembocou numa completa internacionalização da situação interna da Colômbia, evidenciada no Plano Colômbia, financiado quase que exclusivamente pelos EUA. Do lado colombiano, no início de seu governo, Andrés Pastrana apresentou o seu plano de desenvolvimento, denominado "Cambio para construir la paz 1998-2002", no qual, por um lado, apostava numa solução negociada com os movimentos insurgentes, e, por outro, sustentava que o cultivo de substâncias ilícitas era, antes de tudo, um problema social que deveria ser tratado de forma multilateral mediante uma espécie de "Plano Marshall" para Colômbia. Nos termos do plano, tratava-se de "internacionalizar a paz para 'desinternacionalizar' o conflito", ou seja, buscar recursos de governos e organismos multilaterais para fortalecer institucionalmente o Estado e desenvolver a economia, criando condiçóes econômicas, sociais e ambientais que propiciassem uma paz integral (Restrepo, 2001). Porém, a falta de envolvimento pleno da comunidade internacional, sobretudo financeiro, e as dificuldades estruturais para cumprir os objetivos do plano inviabilizaram essa estratégia. Nesse sentido, o governo colombiano passou a considerar outra perspectiva, que foi recorrer a uma aliança tática com os EUA para a resolução da sua situação interna. Não foi em vão que, em setembro de 1999, quando mostrou sua versão do Plano Colômbia aos norte-americanos, o presidente Pastrana, interessado na ajuda econômica desse país, já havia mudado seu diagnóstico e estratégia, apresentando a Colômbia como um país "problema", incapaz de garantir os monopólios estatais do uso da força e do controle do território, diante do poder crescente do narcotráfico e das guerrilhas. (Tickner, 2007). Ou seja, buscava o apoio dos EUA para a resolução dos seus problemas internos, dentro da linguagem que os norte-americanos estavam dispostos a cooperar. Estava de volta, de forma evidente, o espírito da Respice Polum. Nascia, assim, a versão norte-americana do Plano Colômbia, escrita apenas em inglês, baseada essencialmente na sua política antidrogas. 
Do lado dos EUA, embora inicialmente o governo Clinton tenha apoiado o primeiro plano de paz de Pastrana, uma conjunção de percepçóes e interesses - de diversas forças políticas e econômicas que possuem peso na elaboração da política externa norte-americana - sobre a situação colombiana, levou o país a atender aos pedidos da Colômbia por mais recursos financeiros, porém, a destinação dos recursos ocorreria de acordo com as visões, estratégias e objetivos norte-americanos. Em outros termos, as percepções negativas do Departamento de Defesa dos EUA sobre a capacidade do Estado colombiano para enfrentar os conflitos internos, aliadas aos interesses econômicos e geopolíticos dos grupos de pressão, da comunidade de experts e da composição partidária e ideológica do Congresso dos EUA naquele momento, levaram o governo norte-americano a intervir diretamente com um pacote de ajuda, fundamentalmente militar, para a Colômbia, baseado na sua histórica visão sobre o problema do narcotráfico (Rivillas, 2002).

O Plano Colômbia, previsto inicialmente para durar até dezembro de 2005, previa um investimento de US\$7,5 bilhōes, dos quais os EUA forneceriam US \$ 1,3 bilhão (US $\$ 47$ milhões para o Equador). O governo colombiano aplicaria US $\$ 4$ bilhôes, sendo que $80 \%$ dos recursos viriam de financiamento externo e $20 \%$ de ajuste fiscal e de impostos sob controle do FMI, e o restante viria de países europeus e instituições internacionais. Foram muitos e controversos os aspectos que envolveram a criação desse plano, transcendendo inclusive à própria dimensão do combate às drogas. No que se refere à questão de luta contra o narcotráfico, o plano teve como linha mestra a política norte-americana, que estabelece o consumo de droga no seu país não como um problema de demanda interna, mas como de oferta externa, traduzindo-se imediatamente numa estratégia baseada na erradicação dos cultivos mediante a fumigação e a militarização do combate nos países produtores. Nesse sentido, embora o plano contemplasse propostas sociais, econômicas, políticas, jurídicas e de Direitos Humanos, o caráter bélico e repressor constituiu o seu eixo central, consumindo a maior parte dos recursos. Outra questão a ser notada é que parte do montante financeiro inicial destinado a fins militares na Colômbia foi utilizada diretamente para a compra de serviços e equipamentos militares de empresas norte-americanas, como a Bell Textron, a Lockheed Martin, a Military Professional Resources e a United Technologies. Esse plano colocou a Colômbia no seleto grupo composto por Israel, Turquia e Egito, principais países receptores de armamentos pesados e semipesados, treinamento de forças de elite e de assessoria em inteligência militar por parte dos EUA.

Em larga medida, pode-se dizer que essa dimensão militarista também teve como alvo a expansão das ações das Forças Armadas Revolucionárias da Colômbia (FARC) e do Exército de Libertação Nacional (ELN) no conflito interno colombiano, dando ao plano um caráter antiinsurgente, ainda que de forma velada, pois, oficialmente, o Congresso norte-americano limitou as ações ao combate ao narcotráfico. A crescente utilização de recursos econômicos do narcotráfico pelas guerrilhas serviu para os EUA unificarem os problemas do narcotráfico e das 
guerrilhas, sob o tema de combate à narcoguerrilha. Importa destacar que, além das relações com o narcotráfico, as ações das guerrilhas colocavam problemas aos interesses e princípios dos EUA no país, na medida em que as FARC e a ELN se colocavam contra a agenda neoliberal do "Consenso de Washington", atacavam e extorquiam corporaçôes norte-americanas, geravam instabilidade regional e cometiam sequestros e assassinatos contra cidadãos dos EUA. Assim, assessorados por estrategistas militares norte-americanos e apoiados por uma ampla base tecnológica de radares, aviōes, helicópteros e materiais bélicos disponibilizados ou vendidos pelos EUA, as Forças Armadas do Estado colombiano passaram a aplicar uma dura ofensiva contra os grupos guerrilheiros. ${ }^{1}$ Por fim, essa crescente militarização promovida pelo Plano Colômbia também teve como objetivo garantir a segurança e os interesses econômicos de grandes corporaçôes dos EUA presentes no país. Sob esse aspecto, as atividades das companhias petrolíferas norte-americanas na região assumem a maior relevância, e as corporações são muitas: OXY, Texaco, Harken, Chevron, BP-Amoco, Reliant, Eron, Global, Halliburton. Estudos da Associação Internacional de Jornalismo Investigativo (ICIJ), com sede em Washington, revelaram que a aprovação do Plano Colômbia pelo Congresso norte-americano ocorreu mediante um pesado lobby de empresas petrolíferas interessadas nas reservas colombianas e na segurança de seus negócios no país. Segundo a investigação, entre 1995 e 2000, essas companhias investiram US\$ 92 milhôes em lobby para a aprovação do projeto. ${ }^{2}$

Pode-se dizer que, com a adoção do Plano Colômbia, a Colômbia incorporou definitivamente a estratégia militarizada norte-americana de combate ao narcotráfico, com os EUA reeditando sua antiga estratégia da "Guerra de baixa intensidade", na qual oferecem recursos econômicos, logísticos e militares para que seus aliados possam implementar seus combates internos em sintonia com os objetivos norte-americanos.

1 Oficialmente, em dezembro de 2002, o governo de Andrés Pastrana rompeu os diálogos com as FARC e

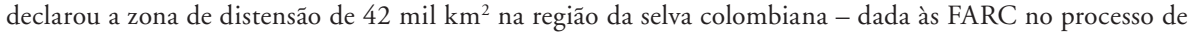
negociação do acordo de paz iniciada em 1998 - como objetivo militar do Estado colombiano. Entre 1998 e 2001, nos marcos do Cambio para Construir la Paz 1998-2002 do presidente Pastrana, as FARC dialogaram com o governo, com executivos de corporações transnacionais, com comissões do Senado e da Câmara, com políticos de todos os partidos, jornalistas estrangeiros, sindicatos e estudantes, sempre com transmissão da TV estatal. Porém, o processo de paz fracassou. Para a classe política tradicional, a razão do fracasso foi a generosidade do governo, que, ao ceder território para as FARC, proporcionou o seu reagrupamento, treinamento e armamento. Do lado das FARC, Marulanda Vélez justificou o fracasso do acordo com a posição intransigente do governo para negociar temas fundamentais na agenda dos guerrilheiros, tais como: o referendo, a participação política com igualdade de garantias e o fim do bipartidarismo; a questão da terra; a ruptura com a política econômica neoliberal; e o fim do Plano Colômbia e da intervenção norte-americana (Orozco, 2004). Seja como for, o fato é que a evidente falta de interesse das FARC para negociar um acordo de paz, nos termos propostos pelo governo, abalou sua credibilidade interna e externa, contribuindo para que seus opositores tivessem mais argumentos para não reconhecê-las como ator político, qualificando-as como grupo terrorista. Até mesmo organismos internacionais, como a União Européia, catalogaram as FARC nas suas listas de organizações terroristas.

2 Ver investigação completa em "Proyeto sobre la ayuda militar de los Estados Unidos a América Latina" (http://www. publicintegrity. org). 
Vistos em conjunto, todos esses fatos que envolveram a formulação do Plano Colômbia nos remetem a vários elementos fundamentais das relaçôes ColômbiaEUA discutidos até aqui. Não é difícil constatar, por exemplo, que se trata de relaçôes completamente assimétricas, nas quais prevalecem a agenda dos EUA, bem como suas definições, diagnósticos e estratégias acerca do tema. No que se refere ao lado norte-americano, parece ter ficado evidente que sua relação com a Colômbia depende de como se definem os interesses e os objetivos gerais de sua política externa, levando em conta sua segurança nacional, suas políticas domésticas e os interesses de suas grandes empresas. Nessa perspectiva, dependendo dessas condições, a Colômbia pode ter uma atenção maior ou menor dos EUA. Do lado colombiano, a recorrência ao Respice Polum como estratégia de política externa para viabilizar a agenda interna faz que, inevitavelmente, suas elites governantes tentem vincular os assuntos do país aos interesses e temáticas centrais da política externa norte-americana, sob pena de perder importância na agenda dos EUA. Essa opção traz benefícios, como a recepção de grandes recursos econômicos e militares para um Estado debilitado, porém pode trazer vários custos, como verificaremos a seguir, entre eles, a falta de autonomia para formular a política externa e a possibilidade de alteraçóes nas prioridades de interesses da política externa norte-americana.

\section{Álvaro Uribe e a política de segurança dos EUA no pós-11 de Setembro}

Todas essas estratégias que envolveram a criação do Plano Colômbia ganharam mais vigor com a conjuntura criada no início deste século, que apresentava, do lado colombiano, a ruptura do processo de negociação de paz com a guerrilha, a exigência de grande parcela da população pelo fim do conflito interno armado e a eleição do outsider Álvaro Uribe Vélez (2002-2006), e, do lado norte-americano, a publicação da nova doutrina antiterrorista do governo Bush após o 11 de Setembro. Álvaro Uribe e George W. Bush, seguindo suas respectivas estratégias, interesses e objetivos, compartilharam a idéia de que as guerrilhas são grupos de terroristas que controlam o narcotráfico e ameaçam a segurança regional e mundial. Logo após sua posse, interessado em avançar na estratégia de internacionalização dos conflitos internos para cumprir sua agenda doméstica, Álvaro Uribe afirmava que: "Na Colômbia não existe guerra, aqui temos terrorismo de grupos armados contra o Estado e a sociedade, e, isto deve ser resolvido rapidamente" (Uribe apud Quiroga, 2003: 164). No mesmo sentido e na mesma época, com interesses econômicos ligados ao petróleo, gás natural e carvão e reafirmando os compromissos norteamericanos com a democracia, a segurança hemisférica, o livre comércio e os Direitos Humanos, o governo dos EUA se pronunciava por meio do seu Secretário de Estado para assuntos do Hemisfério Ocidental, Otto J. Reich, dizendo que: "A Colômbia pode derrotar os terroristas, mas necessita de ajuda dos amigos. Nossos valores, nossa segurança e o futuro do nosso continente estão ligados à 
vitória da Colômbia em sua guerra contra o terrorismo [...] O presidente Bush já pediu ao Congresso autorização para oferecer ajuda militar e de inteligência ao governo colombiano para sua guerra contra o terror" (The Washington Times, 19/6/2002). Portanto, o Plano Colômbia foi inserido na estratégia norte-americana de combate ao terrorismo, transformando o governo de Uribe num grande aliado da nova política de segurança dos EUA. ${ }^{3}$ Com Bush e Uribe, ficou estabelecido publicamente o caráter antiinsurgente do Plano Colômbia. Assim, o conflito interno colombiano se transformou numa frente adicional da guerra dos EUA contra o terrorismo internacional, com os norte-americanos ampliando o seu papel na situação doméstica colombiana, mediante seus diagnósticos, políticas e interesses. Os resultados desse processo serão analisados mais à frente, mas não custa, desde já, concordar com a observação de Pablo Celi (2007), de que as definiçôes de segurança difundidas pelos EUA podem representar vários problemas para os países que as adotam integralmente, pois, sujeitas a fatores ideológicos e outros interesses, essas definiçōes induzem percepções equivocadas das realidades locais, impedindo seu melhor conhecimento e tratamento.

Com o apoio dos EUA e de diversos setores da sociedade colombiana, o presidente Uribe colocou em ação sua política interna, com a chamada "Política de Segurança Democrática", com o objetivo de recuperar "a legitimidade, a legalidade e a governabilidade do Estado colombiano", com destaque para os seguintes pontos: o controle do território e da soberania nacional; a segurança dos cidadãos; o combate às drogas ilícitas e ao crime organizado; o fortalecimento do serviço de Justiça; o desenvolvimento das regiōes pobres e de conflito, com programas produtivos e de paz; a promoção e a proteção dos Direitos Humanos; e a cooperação em programas bilaterais e multilaterais para a proteção das fronteiras (Departamento Nacional de Planeación, 2003). Para atingir essas metas, Uribe, em seu primeiro mandato presidencial, tomou uma série de medidas, tais como: a criação de uma rede de informantes em toda a sociedade, com programas de recompensa para as pessoas que delatassem os colaboradores de grupos insurgentes ou criminosos; a colocação de tropas do Exército e da polícia para garantir a segurança nas estradas; a solicitação do aumento da ajuda econômica dos EUA para não somente manter a política de erradicação dos cultivos ilícitos via fumigações, como também combater as ações das guerrilhas; o aumento das forças do Exército com o recrutamento de "soldados camponeses", etc. Além disso, o presidente Uribe decretou o Estado de Comoção Interior, em 2002, que permitiu ao governo elevar impostos para aumentar o efetivo das Forças Armadas e policiais, autorizar prisōes sem ordens judiciais e instituir a possibilidade de detenção de pessoas com base em suspeitas de intençōes de cometer delitos. Em conjunto, para enfrentar os grupos armados ilegais, a "Política de Segurança Democrática" exigiu um aumento do gasto

3 A concentração da agenda externa colombiana na relação com os EUA levou o governo de Álvaro Uribe apoiar a invasão militar norte-americana no Iraque em 2003. 
público destinado à segurança e defesa, um aumento do efetivo da Força Pública, uma mudança na doutrina operacional e uma modificação progressiva do marco legal e institucional para garantir a ofensiva contra esses grupos (Coyuntura de Seguridad 23, 2008).

Pode-se dizer que, no que diz respeito ao conflito com as guerrilhas, a estratégia de Álvaro Uribe esteve, durante o seu primeiro mandato, calcada no confronto militar para exterminar ou forçar a rendição desses grupos, conforme a frase do próprio presidente em seu Plano Nacional de Desenvolvimento: "A via do diálogo no meio do conflito está esgotada [...] A paz não se negocia, se constrói." Inicialmente, as forças militares de segurança lançaram uma dura ofensiva que expulsou as FARC de lugares estratégicos nos Departamentos de Cundinamarca e Antioquia, recuperando o controle de zonas próximas aos grandes centros urbanos, rodovias e infra-estrutura. Além disso, o governo Uribe recusou qualquer tipo de negociação com os guerrilheiros, rejeitando, inclusive, a proposta das FARC de trocar seqüestrados por guerrilheiros encarcerados, fato que contrariou os familiares dos prisioneiros e os grupos de Direitos Humanos que eram a favor da troca humanitária. Como observou, entre outros estudiosos do assunto, Sandra Borda Guzmán (2007, 71): "a estratégia militarista do governo colombiano debilitou as posiçóes alternativas que preconizavam uma saída negociada para o conflito". Tal posição custou à vida de muitas pessoas, que acabaram sendo assassinadas pela guerrilha. Aliás, nesse particular, o permanente assassinato de civis pelas FARC tem implicado, entre outras questóes, na perda dos derradeiros apoios políticos que esse grupo possui na sociedade colombiana e no exterior, no reforço da caracterização de suas atividades como "terroristas" e no endurecimento da repressão governamental contra os movimentos sociais que atuam no campo da esquerda democrática.

Ainda no que diz respeito às FARC, o aumento do respaldo econômico e militar dos EUA permitiu ao governo Uribe lançar, em maio de 2004, o Plano Patriota, que se constituiu na mais ambiciosa ofensiva militar do Estado colombiano contra os grupos guerrilheiros. O plano se concentrou nas regiōes dos Departamentos Caquetá, Guaviare, Meta e Putumayo, que historicamente serviram como centros de comando, treinamento e retaguarda das FARC. A ação militar envolveu cerca de 18 mil soldados, apoiados, armados, treinados e monitorados pelo Comando Sul das Forças Armadas dos EUA. No primeiro mandato de Álvaro Uribe, ficou evidente que a maior parte da ajuda antidrogas norte-americana se dirigiu às atividades contra-insurgentes, impondo duras derrotas aos grupos guerrilheiros FARC e ELN, sem, no entanto, eliminá-los.

Embora não tenha derrotado completamente as guerrilhas e nem abalado significativamente a indústria da droga, o governo conseguiu impor duros reveses aos guerrilheiros, diminuindo significativamente seu número de membros,

4 Item 57 do Capítulo I, Plano Nacional de Desenvolvimento. 
suas atividades armadas, sua presença territorial, suas açôes de sequestro e sua capacidade de extrair recursos da indústria da cocaína. Nessa questão da relação das guerrilhas com as atividades do narcotráfico, talvez se possa dizer que os resultados dessa política de Uribe condizem com a tese de Mark Peceny e Michael Durnan (2006) sobre a aplicação da política antidrogas dos EUA em situações de conflito armados internos. Segundo esses autores, essa política, em geral, não tem grande efeito sobre a indústria da droga, porém, tem a capacidade de tirar o equilíbrio de forças entre os grupos combatentes no sentido de extrair recursos da indústria da droga, na medida em que resolvem punir, com a não participação nos negócios da droga, um dos lados. Assim, o tratamento diferenciado dados aos grupos armados ilegais no conflito colombiano, tornou as FARC alvo de guerra, enquanto o tratamento mais ameno conferido às Autodefesas Unidas da Colômbia (AUC) facilitou a manutenção desse grupo nos negócios da droga, embora não fosse bem isto que estivesse previsto pelos EUA. Nessa discussão, também vale a pena constatar que o enfraquecimento das guerrilhas não significou alterações na produção e no fluxo das drogas aos EUA, deixando evidente que a questão do narcotráfico no país envolve outros fatores. A importância imprescindível que os recursos do narcotráfico têm para a sobrevivência das FARC não é a mesma que as FARC têm para a sobrevivência dos negócios do narcotráfico, que, inclusive, pode prescindir as FARC.

Se a posição do governo Uribe em relação às guerrilhas foi o confronto, o mesmo não ocorreu no tratamento dado aos paramilitares, no qual, com o aval dos EUA, optou-se pela negociação política. Desde o início do governo houve uma série de negociações com as AUC, que culminaram no Acordo de Santa Fé de Ralito, em julho de 2003, no qual ficou estabelecido que as milícias deveriam promover um imediato cessar-fogo e o desarmamento até o fim de 2005. Em troca o governo ofereceu aos paramilitares garantias de incorporação à vida civil e política, abrindo, inclusive, a possibilidade de atenuar e anistiar as puniçōes sobre os crimes contra a humanidade promovidos por esses grupos. Os resultados desse acordo foram pouco significativos, com os paramilitares se recusando a cumprir temas como a extradição aos EUA, a devolução de fortunas adquiridas ilegalmente e o julgamento de seus delitos em tribunais (Kurtenbach, 2005). Isso levou o governo a estabelecer um novo pacto com as AUC, firmado em maio de 2004, no qual foi criada uma zona de reabilitação para os paramilitares em Tierralta, Córdoba. E o Congresso aprovou, em julho de 2005, a Lei de Justiça e Paz, que estabelecia, entre outros termos, um regime de penas mais brandas (pena máxima de oito anos de prisão), a aplicação da extradição aos EUA somente em caso de ruptura das negociações e a não obrigatoriedade da confissão plena e verdadeira, inclusive para os delitos relacionados ao tráfico de drogas, para obter os benefícios (Caicedo, 2006).

Dados oficiais indicam que, até o final de 2006, quando foi celebrada a última desmobilização das AUC no país, o governo Uribe conseguiu desmobilizar 
cerca de 32. 000 paramilitares. Durante esse processo foram entregues 18. 051 armas, o que, para os analistas, é um número baixo. Para vários membros de organizações humanitárias internacionais e alguns estudiosos do assunto, o governo Uribe, com essas negociações, além de não penalizar como deveria os paramilitares e não ter uma política de reparação para as vítimas das atrocidades promovidas por esses grupos, não combateu explicitamente, em algumas regiões, a histórica relação íntima de membros do governo e das Forças Armadas com os paramilitares para combater as guerrilhas. Instituiçōes como a Human Rights Watch, a Anistia Internacional e o Centro de Investigação e Educação Popular da Colômbia denunciaram, nos últimos anos, que os paramilitares seguiram promovendo violações dos Direitos Humanos depois desses acordos com o governo. Há denúncias também de que o governo não combateu as atividades de narcotráfico desenvolvidas pelos paramilitares, sobretudo nos latifúndios de coca do norte do país. Além disso, apesar dos avanços na desmobilização das AUC, organismos internacionais, como a Internacional Crisis Group (2007) e a Seguridad \& Democracia (2008), constataram as evidências de que a Política de Segurança Democrática não conseguiu eliminar totalmente as atividades dos grupos paramilitares. Novas facçōes, como as Águias Negras, têm surgido e operado em torno de atividades como o tráfico de drogas, homicídios e extorsões, em regiōes de pouca presença estatal ou de antiga presença das AUC, como nos Departamentos de Norte de Santander, Nariño, Córdoba, Valle, La Guajira e Bolivar. Essas facções, que a Oficina do Alto Comissariado das Nações Unidas para os Direitos Humanos (ACNUDH) tem denominado de "novos grupos armados ilegais", são compostas por paramilitares que não se desmobilizaram, paramilitares desmobilizados que regressaram as atividades ilícitas e delinquentes comuns. Esses grupos operam fundamentalmente em torno dos negócios ilícitos do narcotráfico e outras atividades econômicas criminosas. A diferença em relação aos paramilitares das AUC, já desmobilizados, está no fato de que esses grupos não estão coordenados nacionalmente e não possuem um projeto político coletivo. Além disso, esses grupos não têm uma dinâmica contra-insurgente, fazendo, inclusive, em algumas regióes do país, pactos e alianças com grupos guerrilheiros no sentido de preservar os seus ganhos ligados ao narcotráfico. Aliás, nessa questão, quando praticam uma operação contra-insurgente, como tem feito a Organização Nueva Generación (ONG) na região de Nariño, fazem buscando controlar território e

5 Em novembro de 2006, investigações da Corte Suprema levaram à detenção de oito parlamentares da base aliada do presidente Uribe por supostos nexos com as AUC. No mesmo mês, um senador da base de Uribe afirmou que, junto com 40 parlamentares e governadores, assinou em $2001 \mathrm{um}$ pacto com as AUC para defender seus interesses (Jornal Folha de São Paulo, 3/12/2006). Em 22 de fevereiro de 2007 foi preso o ex-chefe da inteligência colombiana Jorge Noguera Costa, sob acusação de envolvimento com as AUC. Jorge Costa comandou o Departamento Administrativo de Segurança durante o primeiro mandato de Uribe, de 2002 a 2006. O "Paragate", como ficou conhecido fora da Colômbia o escândalo sobre o envolvimento de parlamentares da base governista com grupos paramilitares, também revelou o envolvimento de outra pessoa próxima a Uribe, a chanceler María Consuelo Araújo, que acabou renunciando ao cargo. 
populações para dominarem o negócio do narcotráfico (Informe sobre América Latina N. 20, 2007; Coyuntura de Seguridad N. 20, 2008; Ávila y Gantiva, 2008; Vidal y Ortiz, 2008).

No que se refere ao combate às drogas, dados do governo colombiano indicaram uma redução de 46,4\% nos cultivos ilícitos, entre 1999 e 2005 . Assim, os plantios de coca teriam passado de 163.290 hectares, em 1999, para 85. 750, em 2005. Sendo fumigado, no período 1999-2005, um total de 723.125 hectares e erradicados manualmente 61.614 hectares (DNP, 2006: 13). Esses dados não tiraram o país da condição de maior plantador de coca e produtor de cocaína do mundo, sendo responsável por $54 \%$ dos plantios e $65 \%$ da produção, segundo o Relatório da ONU sobre Drogas (2006). De acordo com Diana Marcela Rojas (2007), a redução do plantio não diminuiu a oferta, as drogas ficaram mais puras, e o preço final da cocaína no mercado norte-americano caiu. São muitos os estudiosos e instituições que, a partir dessas informaçôes, apontam para uma ineficácia da política antidrogas dos EUA para resolver o problema. Por fim, vale lembrar que a promessa de Uribe de eliminar totalmente os cultivos de coca no país até 2006 não foi cumprida.

Em conjunto, cabe reconhecer que, apesar do predominante aspecto militar, da limitada atenção às questôes sociais e de direitos humanos e da ineficaz política antidrogas, a "Política de Segurança Democrática", nos marcos do Plano Colômbia, resultou em grande popularidade ao governo Uribe, sobretudo nos setores urbanos. Tanto que a reeleição de Uribe, em maio de 2006, pode ser creditada, em grande parte, a "Política de Segurança Democrática", que garantiu a vinda de investimentos externos, fortaleceu o Estado e melhorou as condições de segurança nos principais centros urbanos do país. Na verdade, as décadas de conflitos e de atrocidades cometidas pelas guerrilhas e pelos paramilitares contra civis desarmados e inocentes fez com que vários setores da sociedade apoiassem uma solução militarizada para o conflito e tolerassem medidas repressivas do Estado em nome de uma determinada segurança (Zuluaga Nieto, 2003).

Com essa breve análise do primeiro governo de Álvaro Uribe, nos marcos do Plano Colômbia e da Política de Segurança Democrática, não é difícil constatar que a Colômbia incorporou várias diretrizes da política de segurança norteamericana para a resolução do seu complexo conflito interno. Mais do que isso, a internacionalização do conflito armado trouxe uma alta dependência do governo colombiano em relação aos EUA em praticamente todos os principais temas do país, tais como o próprio conflito armado, o narcotráfico, o desenvolvimento, o papel do Estado, a democracia etc. Para Diana Marcela Rojas (2009: 122), "a embaixada dos EUA na Colômbia atua como um verdadeiro "superministério", que interage com a maior parte das agências governamentais colombianas". O alinhamento incondicional com os EUA, como saída para seus problemas, tem implicado em relegar a busca de outros espaços na agenda internacional, bem como impedir outras estratégias ou abordagens para o tratamento de questôes 
regionais em termos de segurança, comércio, integração, etc (Reynales, 2004; Rojas, 2006; Guzmán, 2007). Além disso, os termos desse alinhamento têm trazido muitas desconfianças, desentendimentos e atritos nas relações com os demais países andinos.

Ao longo do ano de 2005, na iminência do prazo de encerramento do Plano Colômbia, a administração Bush procurou deixar claro que manteria a intervenção econômica e militar na Colômbia em nome da luta antiterror. Conforme as palavras da secretária de Estado dos EUA, Condoleezza Rice, em visita à Colômbia em maio de 2005:

O Plano Colômbia formal, de cinco anos, está chegando ao fim, mas nosso compromisso com a Colômbia não. A assistência militar, policial, judicial e econômica que estivemos dando fez que a Colômbia estivesse a caminho de uma maior segurança, de cuidar do problema das drogas e de lidar com o narcoterrorismo de maneira eficaz (Jornal Folha de São Paulo, 10/7/2005).

Em reunião com Álvaro Uribe no seu rancho no Texas, em agosto do mesmo ano, o presidente Bush também reafirmou o mesmo compromisso:

Pedirei ao Congresso que mantenha o nosso compromisso para dar prosseguimento aos programas do Plano Colômbia, para que a Colômbia possa continuar com os seus progressos e vencer a sua guerra contra o narcoterrorismo. Nossa parceria estratégica é vital à segurança, à prosperidade e à liberdade de ambos os nossos países e das Américas (Jornal Folha de São Paulo, 5/8/2005).

No mesmo encontro, o governo colombiano fez questão de manifestar o seu alinhamento à política de segurança dos EUA, com as seguintes palavras de Álvaro Uribe: "O grande inimigo da democracia colombiana é o terrorismo" (Jornal Folha de São Paulo, 5/8/2005). E assim, com afinidades e interesses mútuos, o plano foi prorrogado até o começo de 2007, quando Álvaro Uribe, no início do seu segundo mandato, apresentou a Estrategia de Fortalecimiento de la Democracia y Del Desarrollo Social (EFDDS) 2007-2013, também denominada de Plano Colômbia II (DNP, 2007).

Uma breve análise da EFDDS revela que foi mantida a perspectiva de internacionalizar os conflitos internos colombianos, tanto no que diz respeito às temáticas como no que está relacionado ao tratamento dado aos assuntos. Entre os objetivos principais da EFDDS, cabe destacar: a luta contra o narcoterrorismo; o fortalecimento da justiça; a promoção dos Direitos Humanos; a abertura dos mercados; o desenvolvimento social integral; a atenção integral aos desmobilizados; a atenção integral ao desarme e a atenção integral à reinserção. Segundo o Ministério da Defesa colombiano, a essência da EFDDS é a combinação entre o componente militar e a ação integral pela recuperação social e militar do território. 
Note-se que, apesar de continuar prevalecendo a ênfase militar, a atenção integral às questóes sociais foi revigorada nas diretrizes da nova estratégia. Talvez se possa dizer que essa atenção às questôes sociais decorra, por um lado, das críticas sofridas pela Política de Segurança Democrática por não ter apresentado grande avanço nessa área, e, por outro, da necessidade de continuar atraindo recursos financeiros da cooperação internacional e da ajuda humanitária. Seja como for, o fato é que a perspectiva da internacionalização dos conflitos internos foi mantida, até mesmo no calendário da nova proposta, que segue o tempo de duração do mandato presidencial da Casa Branca (2009-2013) e não dos mandatos colombianos (20062010; 2010-2014) (Rojas, 2007).

Outra temática enfatizada na EFDDS que seguiu a aliança com os EUA, esteve relacionada ao tema da abertura dos mercados. Note-se que, desde o início de sua gestão, Álvaro Uribe havia associado o tema comercial ao de segurança na sua relação bilateral com os EUA. Esse empenho pode ser evidenciado nos esforços do governo colombiano pela criação da ALCA, nos moldes propostos pelos EUA, e, depois, com a interrupção das negociações desse acordo, os esforços para a construção de um Tratado de Livre Comércio com os norte-americanos. Também nessa linha, a Colômbia - que tem os EUA como principal destino de suas exportações (principalmente petróleo, carvão e café) e maior provedor de suas importações - já havia conseguido da gestão Bush, em 2002, a ampliação do ATPA (Lei de Preferências Comerciais Andina), que passou a se chamar ATPDEA (Lei de Preferências Alfandegárias Andina e Erradicação de Drogas), conferindo tarifas alfandegárias preferências para os países andinos empenhados na estratégia norte-americana de combate ao narcotráfico. Agora, em 2007, a EFDDS previa avançar nas negociações do tratado bilateral de livre comércio com os EUA, que havia sido firmado com Washington em 22 de novembro de 2006, necessitando aprovação dos Congressos nacionais, porém os ventos da política norte-americana começavam a mudar.

\section{Política externa de Álvaro Uribe e as mudanças políticas nos EUA}

Conforme foi verificado, ao longo do seu primeiro mandato, Álvaro Uribe manteve uma relação privilegiada com a administração George W. Bush e a cúpula do Partido Republicano, tanto que a diplomacia personalista colombiana se deu ao luxo de desmontar a boa relação com o Partido Democrata, herdada da gestão Pastrana. No início do seu segundo governo, Uribe deixou clara a necessidade e a perspectiva de manter uma relação especial com os EUA, no sentido de garantir suas políticas internas. Ocorre que, a partir de novembro de 2006, com a vitória dos democratas nas eleições para o Congresso dos EUA, a política norte-americana começava dar sinais de um novo ciclo, o que, por consequência, trouxe obstáculos às pretensões do governo colombiano. Em pouco tempo, a relação com a Colômbia, que parecia ser um exemplo de caso bem-sucedido da política de segurança norte- 
americana, acabou se transformando em caso exemplar de alguns equívocos dessa política. Ou seja, o novo Congresso dos EUA, refletindo as conjunturas interna e externa, desejava dar novos enfoques e atenções à política externa do país.

Tudo isso teria implicações nas relações EUA-Colômbia. O primeiro semestre de 2007 é emblemático nesse sentido, a rejeição ao Tratado de Livre Comércio (TLC - EUA-Colômbia) e a diminuição dos recursos e reorientação das prioridades do Plano Colômbia pelo Congresso norte-americano deixaram evidente que o jogo de forças e o clima ideológico da política doméstica dos EUA haviam mudado. No caso do TLC, ao mesmo tempo em que o Congresso dos EUA, com a inclusão de algumas normas de proteção trabalhista e ambiental, aprovava os TLC's com o Peru, o Panamá e a Coréia do Sul, vetava o tratado com a Colômbia, com alegação de que esse país não dava mostras concretas de empenho sistemático ao combate dos paramilitares, bem como não havia solucionado os escândalos das relaçóes entre membros do governo e os paramilitares, e, ainda, pouca atenção dava aos Direitos Humanos (Policy Paper 30, 2008). ${ }^{6}$ Em relação ao Plano Colômbia, por sua vez, as pretensões colombianas sofreriam um novo golpe dos Democratas. Pouco interessado nos resultados bélicos do governo Uribe e com as mesmas críticas que inviabilizaram o TLC, o Congresso norte-americano renovou o Plano Colômbia para 2007, com redução da ajuda econômica e reorientação dos gastos. Houve uma redução de $10 \%$ da ajuda econômica, que de U\$ 586 milhões foi para U\$ 527 milhôes. Enquanto os gastos foram reorientados de $76 \%$ do componente militar e $24 \%$ do componente social para 55\% e 45\% respectivamente (Policy Paper, 30, 2008). Também se deve notar que houve incremento de recursos para investigaçôes judiciais em relação aos paramilitares e redução de recursos para a fumigação aérea, ou seja, reparo em temas que vários estudiosos do Plano Colômbia vinham apontando como equivocados há muito tempo.

Em 2008, as perspectivas de manutenção de uma relação privilegiada com os EUA foram diminuindo à medida que, no processo sucessório presidencial norte-americano, os pré-candidatos do Partido Democrata (Hillary Clinton e Barack Obama) mantinham as mesmas posições do partido em relação aos temas da Colômbia, e o governo colombiano não escondia o seu apoio ao candidato Republicano John McCain. Nesse sentido, apesar de todo o empenho pessoal de George W. Bush, que colocou a necessidade do TLC com a Colômbia como um assunto de segurança dos EUA no tabuleiro andino, não houve nenhum avanço nessa área, com o Congresso norte-americano apenas renovando o ATPDEA até dezembro de 2008. Em relação ao Plano Colômbia, foi liberado pelo Congresso o montante de U\$ 545 milhōes para o ano de 2008, com a distribuição dos recursos nos mesmos moldes de 2007. E não surtiram efeito as pressões dos Republicanos

6 Mesmo com a negativa do TLC para a Colômbia, o Congresso dos EUA aprovou a prorrogação do ATPDEA, em 26 de junho de 2007, estendendo as preferências alfandegárias para o país até fevereiro de 2008. 
para que fosse privilegiado novamente o componente militar no pacote de ajuda para o ano de 2009.

Porém, no que diz respeito ao Plano Colômbia, o fato mais importante do ano de 2008 ocorreu em novembro, com a publicação do informe sobre o plano pelo Government Accountability Office (GAO), agência de controle das contas do governo norte-americano. O documento apontou que, entre os anos de 2000 e 2008, os EUA gastaram com o plano a quantia de U\$ 6.130 milhões, sendo U\$ 4.859,5 milhōes na estratégia antidrogas e de segurança, U\$ 1. 031,8 milhōes na promoção do desenvolvimento econômico e social, e U\$ 238,7 milhôes no fortalecimento do Estado de direito. Na estratégia de combate às drogas, o estudo demonstrou que, apesar de ter ocorrido uma redução de $50 \%$ na produção de ópio e heroína, os cultivos de coca atingiram uma área de 157.000 hectares em 2006, representando um aumento de $15 \%$ em relação ao ano de 2000 . Os números não conferem com os informes da ONU e nem com os do governo colombiano. No entanto, o que há de comum nesses relatórios é o reconhecimento de que não houve impacto no fluxo de cocaína aos EUA, ou seja, a estratégia é um fracasso. Porém, essa é uma conclusão que somente a ONU admite categoricamente. Por fim, o documento destacou que a segurança interna do país melhorou, e recomendou que fosse necessário buscar uma estratégia de diminuição da ajuda, embora tenha admitido a existência de uma profunda dependência do governo colombiano em relação ao apoio norte-americano em todas as áreas.

Diante dos trágicos casos do Afeganistão, Colômbia e México, nos quais os EUA gastam bilhões e não equacionam o problema, a nova gestão de Barack Obama (2009-2013) tem feito indicações claras de que possa rever alguns aspectos de sua política de combate às drogas. Não é uma tarefa fácil dentro da sociedade norte-americana, pois a política proibitiva e militarizada é uma construção secular enraizada em vários grupos sociais e políticos no país. Tanto é assim que, recentemente, a secretária Hillary Clinton e o presidente Barack Obama fizeram declarações históricas em que assumem a co-responsabilidade dos EUA pelo problema das drogas (tráfico de armas e demanda), porém, na reunião do Comitê de Entorpecentes da ONU, em março de 2009, os EUA - com o apoio da Rússia, Japão, Itália, Vaticano e Colômbia - vetaram a inclusão do conceito "redução do dano" nas diretrizes da política internacional de combate às drogas. O conceito - apoiado pela Organização Mundial de Saúde, União Européia e grande parte dos países latino-americanos - refere-se às drogas como um problema de saúde pública, prevendo a distribuição de seringas descartáveis a usuários de drogas injetáveis, promoção da higiene e supervisão médica preventiva a doenças que podem ser transmitidas por uso de drogas ilícitas. Tudo indica que, sem abrir mão do combate militar e a lógica proibicionista, a política norte-americana de combate às drogas passe a enfatizar, de fato, enfoques multilaterais e ações nos campos econômicos, sociais, institucionais e de Direitos Humanos. As alteraçôes no Plano Colômbia parecem caminhar nesse sentido. 
Em conjunto, no período compreendido entre a vitória Democrata no Congresso dos EUA em 2006 e os primeiros atos do Governo de Barack Obama em 2009, a personalizada e pouco profissional diplomacia colombiana tem apresentado muitas dificuldades para entender e trabalhar com essas mudanças ocorridas nos EUA, algo que deveria ser básico para um governo que colocou o seu destino na garantia de uma relação privilegiada com os norte-americanos. Básico, porém não tão fácil ideologicamente. Sintonizado com a agenda republicana, centrada no narcotráfico, no livre-comércio e no terrorismo, o projeto conservador de Uribe tem encontrado muitas dificuldades para atender a nova agenda da política norteamericana, sobretudo no tema dos Direitos Humanos. Assim, com reações que vão do espanto à indignação, o governo colombiano vem percebendo que, por conta do novo ambiente político nos EUA, não conseguirá manter as relações com os EUA nos mesmos termos da era Bush. Seja como for, o fato é que, ainda que continue recebendo atenção dos EUA nas questōes do narcotráfico e do terrorismo, a Colômbia vai ter que trabalhar com a mudança nos termos dessa relação, o que exigirá do governo Uribe uma habilidade política interna e externa que ele talvez não tenha, ou por falta de condições ou por falta de disposição.

\section{Referências bibliográficas}

ARANA, Roberto González. La política exterior de Colombia a finales del siglo XX. Investigación y Desarrollo, Vol. 12, No 2, 2004, p. 258-285.

ÁVILA, Ariel; GANTIVA, Magda Paola Nuñez. Expansión territorial y alianzas tácticas. Revista Arcanos, Ano 11, No 14, 2008, p. 52-61.

CAICEDO, Juan Pablo. Amenazas y oportunidades de la estrategia actual de negociación frente al paramilitarismo en el marco de la relación de Colombia con Estados Unidos. Revista de Relaciones Internacionales, Estrategia y Seguridad, Vol. 1, No 1, 2006, p. 35-54.

CARVAJAL, Leonardo. Tres años del gobierno Uribe (2002-2005). Observatorio de análises de los sistemas internacionales (OASIS), No 11, 2005/2006, p. 135-149.

CELI, Pablo. El impacto de las políticas de seguridad en el área andina y las condiciones de la cooperación multilateral. In: CELI, P. (Org.). Integración, seguridad y conflictos en la subregión andina. Quito: Instituto Latinoamericano de Investigaciones Sociales (ILDIS), 2007, p. 43-66.

FUNDACIÓN SEGURIDAD Y DEMOCRACIA. Los grupos armados emergentes en Colombia. Suramérica: ¿Carrera armamentista o renovación militar? Coyuntura de Seguridad, No 20, 2008, p. 5-23.

FUNDACIÓN SEGURIDAD Y DEMOCRACIA. El Debilitamiento de los Grupos Irregulares en Colombia 2002-2008. Coyuntura de Seguridad, No 23, 2008, p. 5-11.

COLOMBIA. Departamento Nacional de Planeación (DNP). Brindar Seguridad Democrática. Plan Nacional de Desarrollo 2002-2006, Bogotá, 2003.

COLOMBIA. Ministerio de Defensa. Politica de Defensa y Seguridade Democrática. Bogotá, 2003. 
COLOMBIA. Departamento Nacional de Planeación. Dirección de Justicia y Seguridad (DJS). 2006. Balance Plan Colombia 1999-2005. Publicado em: http://www. dnp. gov. co/PortalWeb/Portals/0/archivos/documentos/DJS/DJS_Documentos_Publicaciones/ Bal_plan_Col_espanol_final.pdf. Disponibilidade: 25/5/2009.

COLOMBIA. Departamento Nacional de Planeación. Dirección de Justicia y Seguridad (DJS). 2007. Estrategia de Fortalecimiento de la Democracia y el Desarrollo Social (20072013). Publicado em: http://www. dnp. gov. co/PortalWeb/Portals/0/archivos/documentos/ DJS/DJS_Documentos_Publicaciones/estrategia_version_espanol. pdf. Disponibilidade: 25/5/2009.

GUZMÁN, Sandra Borda. La internacionalización del conflicto armado después del 11 de Septiembre: ¡la ejecución de una estrategia diplomática hábil o la simple ocurrencia de lo inevitable? Colombia Internacional, No 65, 2007, p. 66-89.

INTERNATIONAL CRISIS GROUP. Los Nuevos Grupos Armados de Colombia”. Informe sobre América Latina, No 20, 2007, p. 1-37.

JORNAL FOLHA DE SÃO PAULO. Cooperação antiterror agora será explicita. Caderno Mundo, p. A-12, 10/7/2005.

JORNAL FOLHA DE SÃO PAULO. EUA: Bush trata Uribe como vip e defende Plano Colômbia. Caderno Mundo, p. A-15, 5/8/2005.

JORNAL FOLHA DE SÃO PAULO. Paras põem Uribe na berlinda”. Caderno Mundo, p. A-39, 3/12/2006.

KURTENBACH, Sabine. Análisis del conflicto en Colombia. Bogotá: Friedrich Ebert Stiftung, 2005 .

OROZCO, Mario Ramírez. Plan Colombia: ¿Estados Unidos ante un nuevo enemigo en América Latina? Latinoamérica - Revista de Estudios Latinoamericanos, №38, 2004, p. 77-115.

PARDO, Rodrigo; TOKATLIAN, Juan G. Política exterior colombiana. De la subordinación a la autonomía. Bogotá: Tercer Mundo Editores/Ediciones Uniandes, 1988.

PARDO, Rodrigo. Colômbia y EE. UU. Intoxicados por las drogas. In: RAMÍREZ, S.; RESTREPO, L. A. (Org.). Colombia entre la inserción y el aislamiento. Bogotá: Siglo del Hombre/IEPRI, 1997, p. 27-44.

ECENY, Mark;DURNAN, Michael. The FARC's best friend: U.S. antidrug policies and the deepening of Colombia's civil war in the 1990s. Latin American politics and society, Vol. 48, No 2, 2006, p. 95-116.

POLICY PAPER 30. ¿Con el viento en contra? Uribe II y el Congresso Demócrata. De la relación especial al caso ejemplar. Bogotá: Friedrich Ebert Stiftung, 2008.

PUBLIC INTEGRITY. 2001. Proyecto sobre la ayuda militar de los Estados Unidos a América Latina. Publicado em: http://projects. publicintegrity. org/report. aspx?aid=253. Disponibilidade: $12 / 7 / 2001$.

QUIROGA, Antonio Araníbar. El conflicto en Colombia y las Implicaciones para la Región. In: ARAVENA, F. R. (Org.). La Seguridad en América Latina pos 11 de Septiembre. Venezuela: Nueva Sociedad/Flacso-Chile/Woodrow International Wilson Center/Paz y Seguridad en las Américas, 2003. 
RAMÍREZ, Socorro. Integración de Colombia con América del Sur y ALCA. In: ARAUJO, H. V. (Org.). Os países da Comunidade Andina. Brasília: Fundação Alexandre de Gusmão: Instituto de Pesquisa de Relações Internacionais, 2004.

REICH, Otto J. Reich declares support of the government to the Plan Colombia. The Washington Times. Washington, 19/5/2002, p. 23.

RESTREPO, Luis Alberto. (Org.). El Plan Colombia y la internacionalización del conflito. Bogotá: IEPRI/Planeta, 2001.

REYNALES, Nathaly. J. Implicaciones de la securitización en América desde la particularidad colombiana. Investigación y Desarrollo, Vol. 12, No 2, 2004, p. 244-257.

RIAZA, William Restrepo. La política internacional de Estados Unidos y la internacionalización del conflicto colombiano. Estudios Políticos, No 25, 2004, p. 163-192.

RIVILLAS, Borja Díaz. Política exterior de los EE. UU. hacia Colombia: el paquete de ayuda de 1.300 millones de dólares de apoyo al Plan Colombia y la región andina. América Latina Hoy, Vol. 31, 2002, p. 145-186.

RODRIGUES, Thiago. Politica e drogas nas Américas. São Paulo: EDUC/FAPESP, 2004.

ROJAS, Diana Marcela. Balance de la política internacional del gobierno Uribe. Análisis Político, Vol. 19, No 57, 2006, p. 85-105.

ROJAS, Diana Marcela. Plan Colombia II: ¿más de lo mismo?. Colombia Internacional, No 65,2007 , p. 14-37.

ROJAS, Diana Marcela. El taller del imperio global: análisis de la intervención de Estados Unidos en Colombia (1998-2008). Análisis Político, No 65, 2009, p. 111-126.

TENA, Belén Boville Luca. La guerra de la cocaina: drogas, geopolitica y medio ambiente. Madrid: Editorial Debate, 2000.

TICKNER, Arlene B. Tensiones y contradicciones en los objetivos de la política exterior en Colombia. Colombia Internacional, No 49-50, 2000, p. 39-61.

TICKNER, Arlene B. Intervención por invitación. Colombia Internacional, No 65, 2007, p. $90-111$.

U.S. GOVERNMENT ACCOUNTABILITY OFFICE. 2008. PLAN COLOMBIA - Drug reduction goals were not fully met, but security has improved; U.S. Agencies need more detailed plans for reducing assistance. Publicado em: http://www. gao. gov/new. items/d0971. pdf. Disponibilidade: $25 / 5 / 2009$.

UNITED NATIONS. OFFICE ON DRUGS AND CRIME. 2006. World Drug Report. Publicado em: http://www. unodc. org/unodc/en/data-and-analysis/WDR-2006. html. Disponibilidade: 25/5/2009.

VIDAL, Mauricio Romero; Ortiz, Angélica Arias. Bandas Criminales, Seguridad Democrática y corrupción. Revista Arcanos, Ano 11, No 14, 2008, p. 40-51.

ZULUAGA NIETO, Jaime. Colombia: entre la democracia y el autoritarismo. Observatorio Social de América Latina, No 9, 2003, p. 35-51.

Recebido em 23 de junho de 2009 Aprovado em 30 de novembro de 2009 


\section{Resumo}

Este artigo tem como objetivo analisar a dinâmica das relações entre Colômbia e EUA, com ênfase no governo de Álvaro Uribe (2002-...). Para tanto, são examinadas a estratégia de internacionalização do conflito armado colombiano e os aspectos da intervenção dos EUA mediante o Plano Colômbia. Como conclusão, o trabalho sugere que as recentes mudanças políticas nos EUA têm causado impacto nas diretrizes das relações das relações entre EUA e Colômbia.

\section{Abstract}

This article aims to analyze the dynamics of the relationship between Colombia and United States, with emphasis on the Uribe Government. For this purpose, the internationalization strategy of the Colombian armed conflict and the aspects of the U.S. intervention under Plan Colombia were examined. In the final analysis, this paper suggests that recent political changes in the United States have impacted the guidance for U.S. - Colombia relations.

Palavras-chave: Relações Colômbia-Estados Unidos; política exterior; internacionalização do conflito armado.

Key-words: Colombia-United States relations; foreign policy; internationalization of the armed conflict. 